\title{
An Empirical Study of the Effect of Phonetic Teaching on the Listening Ability of Marine College Students-Based on SPSS Software
}

\author{
Caixia Wang, Xiqiu Zhang \\ Shandong Jiaotong University Weihai Shandong
}

Keywords: SPSS; Phonetic Teaching; Listening Ability

\begin{abstract}
Taking sophomores in a marine college as the subjects, the aim of this study is to analyze the effects of phonetic teaching on students' listening ability as well as the correlation between the level of students' pronunciation and listening ability. After the experimental teaching, data are collected and input into Statistical Product and Service Solutions (SPSS) software. Descriptive statistics of the data, independent samples t-test, paired samples t-test and Pearson correlation analysis are carried out. The results show that the listening ability of the students in the experimental class with phonetic training is significantly different from those in the control class, and the students' pronunciation level and listening ability is significantly and positively correlated.
\end{abstract}

\section{Introduction}

After graduation, most students in marine college work on international vessels. Using English to communicate in real time is the characteristic of working on board, so the requirement for the crew's listening ability is becoming higher and higher. An important factor that affects listening ability is pronunciation.

Fan Lianyi and Nang Honghan (2005) confirmed that the phonetic teaching was pretty helpful to the listening comprehension of non- English major college students [1]. Guo Yan (2007) analyzed the correlation between the scores of listening and pronunciation [2]. In recent years, with the rapid development of computer technology, as well as the importance of English as an international language, the second language acquisition research has developed rapidly both at home and abroad. One of the eight hot issues in the research of the second language acquisition is the second language phonetic teaching (Wang Lifei, Sun Xiaokun, 2007) [3]. Learners' pronunciation is considered to be one of the most important factors (Chen Yan,2014) [4].

The study is designed to explore the effect of phonetic teaching on the listening ability of Marine College Students. The phonetic teaching is given to the experimental group and the relevant data collected. To deal with the large amount of data is a delicate and tedious work, so a powerful software, Statistical Product and Service Solutions (SPSS) is employed in this study, which has widely applied in various fields.

\section{Phonetic Teaching}

In this study, Thornbury's top-down approach in phonetic teaching is adopted, which focuses on practical, simple theory. By taking this method, students' attention is led from the correct pronunciation of a word to the coherent discourse. It puts much emphasis on liaison, loss of plosion, assimilation, stress, rhythm, pause, intonation etc.

\section{Research Design}

\subsection{Research questions}

This study mainly focuses on the following three questions: (1) Is there a difference in the listening comprehension test at the end of the semester between the experimental group and the control group? (2) Is the Students' pronunciation level related to their listening ability? If so, how much are they related? (3) What is the view of the experimental group students to the phonetic 
teaching?

\subsection{Research subjects}

The research subjects are male sophomores of two natural classes in a marine college. Before the experiment, the research subjects were carefully selected. There were no significant differences in average English comprehensive ability, listening ability and pronunciation level in these two classes, one as the experimental group, 38 people and the other as the control group, 39 people. The students in these two classes were given pronunciation training for a semester with same periods by the same teacher, using the same teaching materials. Due to the semi-military management in the marine college, students' learning time after class was basically the same.

\subsection{Research instruments and data collection}

The instruments used in this study were the first test, post test and interview. The subjects' listening ability and pronunciation level before and after the experiment were graded. All the subjects were interviewed after the experiment. The test papers for the first test and post test for the listening ability and pronunciation level came from listening comprehension test and oral part respectively of Public English Test System (PETS3). The teacher who gave the grade was experienced in PETS test. The subjects' scores were converted into hundred-mark system.

After all data were entered into the computer, descriptive statistics of the data, independent samples t-test and paired samples t-test were carried out to verify the subjects' listening ability before and after the experiment by using statistical software (SPSS 17.0). Pearson correlation analysis on the pronunciation scores and listening scores of the subjects was carried out. Then the subjects' attitudes and opinions in the experimental group on phonetic teaching were obtained by interviews.

\section{Results and Discussion}

\subsection{Comparison on two groups' listening ability after the experiment}

Table 1 descriptive statistics of listening ability after the experiment Between the experimental group(EG) and control group(CG)

\begin{tabular}{|l|l|l|l|l|l|}
\hline \multicolumn{3}{|l|}{ Group statistics } & \multicolumn{5}{|l|}{ subjects } & $\mathrm{N}$ & $\begin{array}{l}\text { Mean } \\
\text { Value }\end{array}$ & standard & Standard error \\
\hline \multirow{3}{*}{ Listening } & deviation & of mean value \\
\cline { 2 - 6 } & EG after the & 38 & 78.1053 & 7.30712 & 1.18537 \\
& experiment & & & & \\
\cline { 2 - 6 } & CG after the & 39 & 73.8462 & 6.79605 & \multirow{2}{*}{1.08824} \\
\hline
\end{tabular}

After a semester of teaching experiment, the subjects were tested on listening ability for the second time. The results were tested by independent samples t-test, as shown in Table 1 and Table 2 . As it can be seen from Table 1, there is a certain gap on the listening scores between the experimental group and the control group. The mean value is 78.105 ( $\mathrm{SD}=7.307$ ) and 73.846 $(\mathrm{SD}=6.796)$ respectively. As it can be seen from Table 2, Levene test of variance equation $\mathrm{F}$ is .176, Sig. is $0.676, \mathrm{t}$ is 2.649 , mean difference is 4.259 . Sig. (bilateral) is .01, which is less than significant level 0.05 . It indicates that there is a significant difference between the two independent samples, in other words, about the listening scores after the experiment, there is a significant difference between the experimental group and the control group. In addition, the average difference between the $95 \%$ confidence interval does not contain 0 , also indicates the difference between the two groups is significant. 
Table2 independent samples t-test of listening ability after the experiment between EG and CGindependent samples t-test

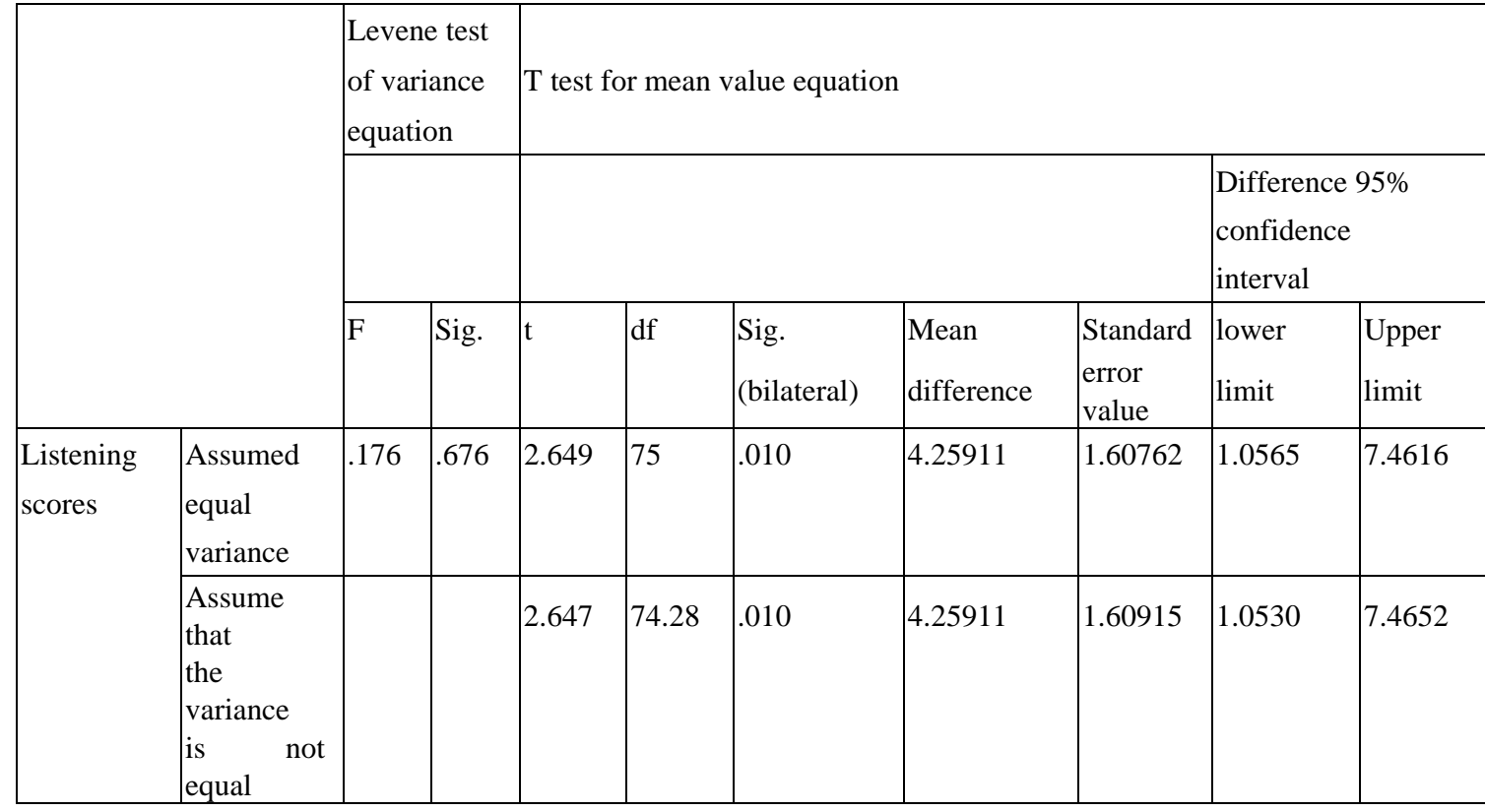

4.2. The correlation between pronunciation scores and listening scores in the experimental group after the teaching experiment

Correlation analysis was made on pronunciation scores and listening scores. To be concise, the results were summarized and sorted out and the correlation coefficient between pronunciation scores and listening scores was shown in Table 3.

Table3 The correlation coefficient between pronunciation scores and listening scores

\begin{tabular}{|l|l|l|l|l|}
\hline & $\mathrm{A}$ & $\mathrm{B}$ & $\mathrm{C}$ & $\mathrm{D}$ \\
\hline $\begin{array}{l}\text { Pearson } \\
\text { correlation } \\
\text { coefficient }\end{array}$ & $0.682^{* *}$ & $0.787^{* *}$ & $0.677^{* *}$ & $0.649^{* *}$ \\
\hline Sig.(bilateral) & 0.002 & 0.000 & 0.000 & 0.001 \\
\hline $\mathrm{N}$ & 38 & 38 & 39 & 39 \\
\hline
\end{tabular}

** At.01 level (bilateral) was significantly correlated

A: pronunciation scores and listening scores in the experimental group before the experiment

B: pronunciation scores and listening scores in the experimental group after the experiment

C: pronunciation scores and listening scores in the control group before the experiment

$\mathrm{D}$ : pronunciation scores and listening scores in the control group after the experiment

As it can be seen from table 3, the overall trend is: whether the experimental group or the control group, whether it is the former test results or post test scores, pronunciation scores and listening scores were significantly and positively correlated. There is a high correlation between the level of students' pronunciation and their listening ability, which may be related to the students' hometown in our college. In recent years, more and more marine students come from western region and remote mountain area. According to incomplete statistics, these students account for $1 / 2$, who have a relatively poor command of English; What's more, students are almost male in a marine college due to the special nature of navigation. There is a gender difference in English learning, generally speaking, female learners' language acquisition ability is better than male learners. Another explanation is that pronunciation level has a greater impact on listening ability and the correlation between them is more significant, compared with other factors such as listening strategies and other factors affecting the level of listening when learners have a poor listening ability.

\subsection{The students' attitudes towards phonetic teaching}

At the end of the experiment, the subjects in the experimental group were interviewed. 94\% 
students think that their pronunciation level has been greatly improved because of the phonetic teaching. When they were asked about the impact of the phonetic teaching on their listening ability, some students said, "My pronunciation was poor before, what the foreigners talked sounded strange to me. After the phonetic training, it's much easier and more accurate for me to distinguish the words I heard."

\section{Conclusions}

According to the above quantitative and qualitative analysis, it shows that phonetic teaching plays a great role in improving the listening ability of the students in the marine college. Students' pronunciation level and listening ability are significantly and positively correlated. At present, the teaching tasks of Marine College are heavy, and students' learning pressure has been very great because of theory courses and trainings for all kinds of certificates. Owing to the close relationship between pronunciation level and listening ability, English pronunciation as a free selective course is recommended if the normal teaching plan in a marine college is not able to squeeze time for it. In this way, students with poor pronunciation may have the opportunity to improve their pronunciation, and then their listening ability can be improved at the same time. There are limitations in this study, for example, the experiment time of phonetic teaching is only one semester, and the time is relatively short; The number and the type of research subjects are limited; In this experiment, while taking all possible measures to control variables, it is very difficult to completely control all variable factors.

\section{References}

[1] Fan Lianyi and Nang Honghan. A survey report on English phonetic teaching to non-English major students. Journal of Xi'an College of Foreign Languages, 2005, (12): 22-24.

[2] Guo Yan. An Empirical Study on the Necessity of College English Phonetic Teaching, 2007(11): 46.

[3] Wang Lifei and Sun Xiaokun. Progress in the study of second language acquisition in foreign countries. Foreign language and foreign language teaching, 2007, (4):25-29.

[4] CHEN Yan. A Research on the Relativity between English Phonetic Factors and English Listening Comprehension. Overseas English 2014(1). 